\title{
Redes institucionales y desarrollo económico en ciudades pequeñas: el caso de la localidad de Pigüé (Argentina)
}

José Ignacio Diez. Universidad Nacional del Sur, Bahía Blanca, Argentina. Nicolás Urtizberea. Universidad Nacional del Sur, Bahía Blanca, Argentina.

RESUMEN | En las últimas décadas, las ciudades de dimensión y rango pequeño han recuperado su protagonismo dentro de los sistemas urbanos, tanto en el ámbito de la bibliografía científica como en las estrategias de ordenamiento y desarrollo territorial a escala internacional. Al igual que lo sucedido en la década de los sesenta, estas localidades están adquiriendo preponderancia como componentes destacados de las políticas de desarrollo regional, incorporándose como actores clave en las posibilidades de despegue industrial de territorios periféricos. Entre los instrumentos tendientes a promover su crecimiento y consolidación, la literatura especializada destaca la conformación de redes institucionales como un elemento capaz de incentivar la innovación y el cambio tecnológico. En esta línea, se sostiene que en las ciudades pequeñas y medias más exitosas a escala internacional, la existencia de un tejido institucional denso y complejo ha sido determinante para garantizar una adecuada competitividad de base territorial. El presente trabajo pretende analizar la dinámica de funcionamiento de la red de organizaciones de apoyo a la producción (OAP) de la localidad de Pigüé (Argentina), con el propósito de entender en qué medida estas instituciones mejoran las condiciones de competencia y desarrollo del territorio.

PALABRAS CLAVE | redes, desarrollo territorial, competitividad urbana, geografía económica.

ABSTRACT | During reent decades, small cities have recovered their importance in the context of urban systems, both in the field of scientific literature and in the field of development strategies at a global scale. As in the 1960s, such towns are acquiring preponderance as main components of regional development policies, being recognized as key actors in the stimulation of industrial possibilities for peripheral territories. Among the instruments ai $i$ med at promoting the growth of such cities, the literature emphasizes the creation of institutional networks, as an element capable of encouraging innovation and technological change. In this sense, it is argued that in small and medium cities that are more successfully inserted into the global economy, the existence of institutional density has been crucial to ensure territorial competitiveness.

This paper analyzes how institutional networks operate in a small town called Pigüe in Argentina, in an effort to understand the way in which these organizations can improve the competitive conditions and development opportunities for this territory.

KEYWORDs | networks, territorial development, urban competitiveness, economic geography.

Recibido el 4 de marzo de 2013, aprobado el 2 de enero de 2014

E-mail: José Ignacio Diez, jdiez@uns.edu.ar | Nicolás Urtizberea, nurtizberea@gmail.com

Correspondencia: Departamento de Economía Universidad Nacional del Sur, 12 de Octubre 11987 mo Piso (12 de Octubre y San Juan),

CP 8000 Bahía Blanca, Argentina 


\section{Introducción}

A comienzos del tercer milenio, las profundas alteraciones tecnológicas, productivas e institucionales registradas a escala planetaria, están produciendo cambios significativos en la geografía de las actividades económicas.

A lo largo y ancho de América Latina, se están evidenciando fuertes reestructuraciones espaciales producto de los intentos de los distintos países por insertarse adecuadamente en la economía mundial. En este contexto, se han registrado cambios estructurales a través de la ocupación de nuevos espacios y la resignificación de otros, tanto urbanos como rurales.

A través de este proceso de resignificación del territorio, las ciudades pequeñas cobran un nuevo protagonismo dentro de los sistemas urbanos. Al igual que lo sucedido en la década de los sesenta, estas localidades están adquiriendo preponderancia como componentes destacados de las políticas de desarrollo regional, incorporándose como actores clave en las posibilidades de despegue industrial de territorios periféricos.

Tradicionalmente, las ciudades pequeñas cumplieron un doble rol. En primer término, fueron concebidas como centros de servicios dedicados a funciones terciarias de segundo nivel. En segundo lugar, se transformaron en cabecera de sectores industriales maduros, habitualmente subvencionados a través de políticas de distinta índole-como, por ejemplo, ayudas financieras o desgravaciones impositivas-, con el propósito de facilitar la radicación de empresas. Además, estas localidades fueron objeto de políticas de polarización (Perroux, 1955; Boudeville, 1965), destinadas a promover encadenamientos productivos y generar externalidades positivas o efectos de difusión, con el objetivo primordial de acumular capital.

Como se sostuvo anteriormente, hoy en día el interés que se produce por estas ciudades se da en un contexto completamente diferente (globalización, crisis del Estado de bienestar, cambios en los regímenes tecnológicos y de acumulación), pero nuevamente se plantea la necesidad de conocer mejor su funcionamiento, para aplicar estrategias de desarrollo que favorezcan su crecimiento y consolidación.

En este marco de carácter general, las redes institucionales emergen como un instrumento idóneo tendiente a alcanzar este objetivo. De este modo, la literatura sobre economía urbana y regional destaca la conformación de estas tramas como un factor capaz de incentivar la innovación, el cambio tecnológico y la acumulación de capital en este tipo de espacios.

En relación con este punto, autores como Vázquez Barquero (1993) sostienen que "en las ciudades pequeñas y medias, la existencia de un tejido institucional denso y complejo ha sido determinante para garantizar una adecuada competitividad de base territorial” (p. 23). Por su parte, Camagni (1991) profundiza esta cuestión sosteniendo que estas redes funcionan suministrando a las empresas capacidades faltantes, potenciando procesos de aprendizaje y realizando informalmente funciones de investigación, transmisión, selección, decodificación, transformación y control de la información, que permiten la emergencia de ventajas cooperativas.

Según Méndez (1997), en los núcleos urbanos de esta naturaleza más dinámicos a nivel internacional, las organizaciones territoriales son portadoras de recursos específicos que, combinados a través del espacio de las redes, generan ventajas 
competitivas capaces de aumentar su atractividad y fertilidad ${ }^{1}$, promoviendo de esta forma procesos de desarrollo económico local.

Desde esta óptica, altos niveles de interacción entre las organizaciones en la forma de contactos regulares, tanto formales como informales y a diferentes niveles, generan flujos de información que terminan traduciéndose en acciones concretas a favor del desarrollo. Esto produce, a lo largo del tiempo, un grado de "isomorfismo mutuo" (Amin \& Thrift, 1995, p. 102), que favorece la construcción de una agenda colectiva de iniciativas tendientes al crecimiento económico. Además, estas formas de interacción pueden generar ciertas normas sociales y hábitos, creando "atmósfera social” (Macleod \& Goodwin, 1999, p. 513) y relaciones de confianza que incentivan el progreso.Por otro lado, la literatura sobre esta problemática sostiene que en los territorios en los cuales estas condiciones están ausentes, el atraso suele ser moneda corriente. No se explotan adecuadamente los recursos, existen bajos niveles de innovación, y esto afecta notablemente el ambiente económico y las decisiones de inversión.

Partiendo de estas premisas, el presente trabajo pretende analizar la dinámica de funcionamiento de la red de organizaciones de apoyo a la producción (OAP) de la localidad de Pigüé en Argentina, con el propósito de entender en qué medida estas instituciones secundan o promueven el crecimiento económico y la acumulación de capital. Por organizaciones de apoyo a la producción se entiende aquellas entidades que, en sus objetivos estatutarios, plantean alcances relacionados con el desarrollo productivo de la localidad y su zona de influencia; entre ellas puede citarse a la banca pública y cooperativa, el gobierno local y los entes públicos no gubernamentales, las organizaciones gremiales empresarias y las instituciones educativas, entre otras.

La hipótesis que guía la presente investigación es que estas entidades no han logrado desarrollar una masa crítica de relaciones, proyectos y actividades, que les permita posicionarse como agentes relevantes en materia de promoción del desarrollo económico del partido.

Con el propósito de corroborar esta presunción, los autores realizaron entrevistas $^{2}$ a dieciséis OAP entre los meses de mayo y julio de 2012. En las mismas se recolectó información concerniente a: i) metas y objetivos organizacionales; ii) trayectoria; iii) vínculos y relaciones entre las mismas; y iv) percepción de sus dirigentes respecto a diversos puntos relacionados con las posibilidades de desarrollo económico local. Para la selección de las instituciones que serían entrevistadas se solicitó la colaboración de informantes clave, personas con un amplio conocimiento respecto a la vida económica e institucional de la localidad.

1 Por atractividad se entiende la capacidad de una localidad para captar inversiones externas directas, mientras que el concepto de fertilidad remite a las competencias que un territorio tiene para incentivar el nacimiento de empresas de capital local.

2 Las entrevistas se basaron mayormente en un conjunto de preguntas abiertas, pero lo suficientemente concisas como para que las respuestas de los referentes consultados puedan ser comparables entre sí, utilizando como base un protocolo y en función de temas guía, surgidos a partir del marco teórico de la investigación. La técnica utilizada fue de embudo, es decir, que se ordenaron las preguntas desde aquellas más generales hacia las más concretas u específicas (Vieytes, 2004). 


\section{Organización del trabajo}

En el presente artículo se describe, en primer término, el marco teórico que da sustento a la investigación. En esta sección se exponen los principales aportes de la literatura especializada respecto al papel de las pequeńas ciudades en los procesos de desarrollo territorial. En su extensión se intenta combinar las miradas de las dos disciplinas sociales que convergen en este estudio -geografía y economía-, integrando elementos de la discusión teórica contemporánea sobre la cuestión urbana, el crecimiento económico y la acumulación de capital. Vale la pena señalar, sin embargo, que de ningún modo esta sección pretende ser una revisión exhaustiva de los múltiples aportes de estas disciplinas al entendimiento del fenómeno, sino un esfuerzo en la construcción de un esquema conceptual que resulta funcional a la presente investigación.

En segundo lugar, se enuncian algunos rasgos fundamentales de la teoría de las redes, poniendo especial énfasis en el papel que tienen las tramas organizacionales como desencadenantes de procesos de desarrollo económico territorial. A su vez, en este apartado también se hace mención a las diferentes técnicas que existen para relevar información sobre la dinámica de funcionamiento de dichas tramas.

En tercer lugar, se realiza una breve presentación del territorio objeto de estudio. Aquí también se menciona en forma sucinta el proceso de gestación de las principales organizaciones del distrito y luego se analiza la comunicación existente entre las mismas. A lo largo de este punto, el esfuerzo de investigación se focaliza en esquematizar los procesos de intercambio de conocimientos e información entre actores, por considerarlos insumo fundamental para el desarrollo de cualquier territorio. Posteriormente, se consideran diferentes medidas de análisis de redes sociales (densidad, grado de centralidad, centralidad de cercanía y grado de intermediación) con el propósito de evaluar estos procesos de comunicación. Estas medidas surgen de la utilización de software especializado a tal efecto ${ }^{3}$.

Esta forma de evaluación de redes, muy utilizada en el ámbito de la antropología social y la sociología, ha ido ganando terreno en los estudios sobre desarrollo económico territorial, principalmente debido a la facilidad que presenta para considerar diferentes niveles de análisis: meso (o de estudio de la trama en su conjunto) y micro (o de posición de cada actor en el contexto de la red). Las medidas que se presentan en el trabajo constituyen una aproximación idónea para el entendimiento de estos dos enfoques.

En quinto término, el artículo muestra cómo el proceso de comunicación vigente en Pigüé se traduce o no en actividades más complejas, como son los proyectos económicos conjuntos, los cuales tienen incidencia sobre el crecimiento y la acumulación de capital a escala local.

Posteriormente, se exhiben algunos resultados respecto a la presencia/ausencia de liderazgos dentro del sistema institucional del partido, con el propósito de entender la capacidad que registra la trama en general y algunos actores en particular para promover esfuerzos concertados. En este punto, la metodología utilizada se

Específicamente se utilizan los programas UCINET 6.45 y Netdraw 2.12. 
encuentra en línea con diversos trabajos desarrollados por la Comisión Económica para América Latina y el Caribe (CEPAL) para distintas localidades de Argentina ${ }^{4}$.

Por último, a modo de conclusión, se presenta un análisis pormenorizado de los indicadores construidos y de los datos relevados, considerando tanto los resultados en términos sistémicos como aquellos que involucran a los actores centrales del entramado analizado.

\section{Ciudades pequeñas: competitividad y desarrollo territorial}

En el mundo actual, hacer mención a la ciudad pequeña implica hablar de un espacio que puede estar relacionado en forma activa con el resto del mundo, pero con un entorno social, cultural, simbólico y morfológico particular. En este contexto de avance sistemático de la urbanización a escala planetaria, el significado de las ciudades pequeńas cambia respecto a lo que sucedía en el pasado ${ }^{5}$.

Anteriormente, en el ámbito de la geografía y de la planificación urbana se veía la creciente urbanización como algo positivo, hasta que, desde inicios de los años setenta, la teoría de los limites del crecimiento (Meadows, Meadows, Randers \& Beherens, 1972) ${ }^{6}$ alteró esta perspectiva. Los problemas de polución, las deseconomías de aglomeración en servicios públicos y equipamiento, las crecientes migraciones internas y el despoblamiento del territorio, ente otros, hicieron reflexionar a los planificadores respecto a la necesidad de buscar un desarrollo urbano más equili$b r a d o^{7}$. Ante esta situación, se produjo una revalorización de las virtudes o ventajas

4 Entre los años 2000 y 2002, la cepal desarrolló estudios sobre densidad institucional en las localidades de Rafaela, Tandil y Mar del Plata.

5 Para el caso argentino, no existe un criterio único que delimite adecuadamente lo que se entiende por ciudad pequeña. Para Sassone $(1992 ; 2000)$, constituyen ciudades de estas características aquellas que oscilan entre los 5.000 y los 20.000 habitantes, mientras que para Vapńarsky (1995; 2004), el límite superior debe extenderse necesariamente hasta una población que ronde las 50.000 personas. Debido a esta cuestión, el criterio que se utiliza para calificar a estos núcleos urbanos está más ligado a su funcionalidad (principalmente económica) dentro del sistema urbano nacional que a la densidad demográfica. Por su parte, dadas las particularidades específicas de la estructura urbana argentina (presencia de una gran metrópoli conurbanizada que concentra a más de $54 \%$ de la población nacional), el papel económico de estas localidades en el interior del país en muchos casos tiende a mimetizarse con el rol económico que cumplen aquellas de tamaño medio o capitales de Provincia.

6 Los limites del crecimiento (en inglés, The Limit to Growth, por D. H. Meadows, D. L. Meadows, J. Randers y W. Behrens, 1972; publicado en español por el Fondo de Cultura Económica, México, 1972) es un informe encargado al Miт por el Club de Roma. El mismo fue publicado en 1972, pocos años antes de la crisis del petróleo. El informe se basa en la simulación informática del programa World3, el cual recrea el crecimiento de la población, el crecimiento económico y el incremento de la huella ecológica de la población sobre la tierra en los próximos cien años, según los datos disponibles hasta la fecha. La tesis principal del libro es que, "en un planeta limitado, las dinámicas de crecimiento exponencial (población y producto per cápita) no son sostenibles”. Así, el planeta pone límites al crecimiento, como los recursos naturales no renovables, la tierra cultivable finita y la capacidad del ecosistema para absorber la polución producto del quehacer humano, entre otros. Estos resultados tuvieron un fuerte impacto en diversas disciplinas, entre ellas la geografía y la economía, permitiendo incorporar a distintas teorías la noción de desarrollo sostenible o sustentable.

7 Existen muchas menciones de organismos y organizaciones internacionales respecto a la necesidad de promover sistemas urbanos más equilibrados. A modo de ejemplo, la Comisión Europea 
de las ciudades pequeñas y su rol de articuladoras y dinamizadoras del desarrollo regional. Históricamente, estos núcleos poblacionales funcionaron como pequeños centros administrativos, espacios concentradores para la provisión de servicios y como centros para la comercialización y venta de productos necesarios para la producción agrícola (Capel, 2009). Posteriormente, luego de la revolución industrial, muchas de estas localidades se transformaron en espacios de radicación de empresas especializadas en sectores maduros, como, por ejemplo, la industria textil y del calzado. A su vez, durante la década de los años sesenta, algunas fueron objeto de diversas políticas que buscaron su crecimiento y consolidación a través de subsidios, créditos e inversión pública, alterando su dinámica, morfología y funcionamiento mediante lo que se conoció como la politica de polos de crecimiento (Paelinck, 1963; Boudeville, 1965).

Sin embargo, hasta entrados los años ochenta, las ventajas económicas de la gran ciudad en relación con los pequeños núcleos urbanos eran muy significativas: externalidades positivas de todo tipo vinculadas a la cercanía, a la posibilidad de establecer mayor cantidad de relaciones sociales, a la educación, a la disponibilidad de centros científicos y a la variedad del mercado trabajo. Hoy en día, sin embargo, motivo de la creciente internacionalización de las telecomunicaciones y del desarrollo masivo de los medios de transporte, estas ventajas parecen estar disminuyendo, ya que la mayor conectividad mejora notablemente las capacidades competitivas de las pequeńas ciudades. En este sentido, esos pequeńos espacios se constituyen no solamente en ámbitos propicios para el buen vivir, sino también en lugares adecuados para el desarrollo de emprendimientos productivos de cierta envergadura.

Por otro lado, una utilización más adecuada de los recursos económicos, sociales, culturales y técnicos de estas sociedades, también estaría permitiendo acortar la brecha competitiva ${ }^{8}$. Entre los instrumentos que permiten la optimización de estos recursos endógenos, se encuentran las redes institucionales. La literatura sobre desarrollo económico territorial destaca el papel que tienen estas tramas de colaboración en la difusión de conocimientos e información y en la consolidación de estrategias de aprendizaje colectivo que repercuten positivamente sobre las potencialidades económicas del territorio.

\section{Las organizaciones, las redes y la competitividad territorial}

\section{La perspectiva teórica del análisis de redes}

Como se sostuvo en la introducción del presente artículo, en la actualidad una parte sustancial de los estudios sobre desarrollo económico local destacan el papel de las redes como un elemento clave para alcanzar una utilización óptima de los factores productivos. Según Méndez (1998), una porción importante del éxito competitivo

propuso en el año 1999 el policentrismo como solución al desarrollo regional europeo, ya que este daría mayor cohesión a las regiones. En dicho informe se destaca el papel de las ciudades pequeńas y medias como elementos estructurantes del territorio (Faludi, 2005).

8 La idea de optimizar el uso de los recursos propios para promover el crecimiento y la acumulación de capital se encuentra bien formulada en el enfoque del desarrollo endógeno (Vázquez Barquero, Boisier, Alburquerque, Arocena, entre otros). 
de diversas localidades de tamaño pequeño y medio en el escenario de la economía mundial está íntimamente ligada al uso que estas sociedades hacen de los recursos genéricos y específicos presentes en el territorio. Bajo este criterio, se entiende por recursos genéricos aquellos factores indiferenciados que existen en la mayor parte de los lugares (recursos naturales, población sin calificación, ahorro disponible para inversión, etcétera), mientras que entre los recursos especificos se consideran a aquellos que se construyen a partir del propio proceso de crecimiento económico y desarrollo (infraestructuras tecnológicas, mano de obra calificada, cultura organizacional y capacidad de gestión, etcétera). En esta óptica, el espacio de las redes y de la acción colectiva permite optimizar la utilización de ambos factores, movilizando recursos que se encuentran subutilizados y/o estableciendo diferentes combinaciones de los mismos, que se traducen a posteriori en una mayor acumulación de capital.

A través de las iniciativas conjuntas, los actores locales se comunican, compartiendo conocimientos y capacidades y construyendo espacios de trabajo común que facilitan el desarrollo de proyectos e innovaciones. Así, los beneficios de la cooperación son múltiples, ya que el trabajo conjunto permite enfrentar problemas complejos que serían imposibles de abordar por un solo actor. De acuerdo con Harrigan (1992), las ventajas de la cooperación son las siguientes:

a. Beneficios internos: las acciones conjuntas permiten que los agentes compartan riesgos, accedan a mejor información y eviten la duplicación de esfuerzos.

b. Beneficios competitivos: la colaboración entre diversos agentes constituye un instrumento eficaz para promover sectores industriales específicos, permitiendo alcanzar un mejor posicionamiento de los mismos en la economía mundial.

c. Beneficios estratégicos: la cooperación promueve la sinergia entre diversos actores, la transferencia de conocimientos y tecnología, y amplía las posibilidades de diversificación de las actividades productivas.

En el caso particular de las redes institucionales, su conformación generalmente apunta al suministro de bienes públicos (planes estratégicos, agendas de desarrollo, etcétera), que de otra forma no se prestarían. Desde esta perspectiva, la conformación de tramas organizacionales constituye un medio para la resolución de problemas de tipo (para)políticos, es decir, casos de búsqueda colectiva de objetivos o realización de propósitos comunes.

De acuerdo con Michael Best (1990), los sistemas de redes permiten diseñar mecanismos de governance dentro de un territorio, que facilitan los procesos de competencia de tipo schumpeteriano, donde la innovación y la creación de mercados resultan fundamentales para el crecimiento económico. En términos del autor, a través del espacio de las redes, las organizaciones del medio pueden comunicarse y coordinar acciones que redundan a posteriori en una mayor acumulación de capital. Este tipo de vínculos incluye la realización de proyectos de colaboración en áreas productivas, científicas, de prestación de servicios, institucionales, de infraestructura y equipamiento. A modo de ejemplo sobre los alcances de este tipo de vínculos, en un trabajo sobre 33 localidades de tamaño pequeño y medio de la Unión Europea, Bennett y Krebs (1994) encontraron que el papel del Estado resulta 
fundamental en la coordinación y consolidación de las redes, siendo las ciudades más exitosas aquellas que lograron crear una estructura estable de gobernabilidad local. Al respecto, los autores notan que la complejidad de las mismas covaría con el grado de desarrollo económico: las ciudades estancadas o en proceso de declive tienen redes fragmentadas y con una configuración de mosaico, mientras que aquellas "ganadoras" presentan múltiples conexiones entre los diferentes actores.

En relación con este punto, los trabajos empíricos sobre la temática muestran que el paso de un modelo de organización del territorio de carácter desarticulado y jerárquico hacia un modelo en forma de red, requiere contar con instituciones dotadas de ciertos umbrales mínimos de recursos humanos y técnicos, que les permitan administrar la complejidad. A estos recursos de carácter tangible, deben sumarse necesariamente aspectos idiosincráticos y culturales que favorezcan el diálogo y la interacción.

En esta línea argumental, Boisier (1997) sostiene que existen cuatro características básicas que definen a una institución capaz de trabajar en forma reticular: la velocidad para reaccionar frente a cambios rápidos en el entorno; la flexibilidad, que posibilita dar respuestas diversas (de grande o pequeña escala, coyunturales o estructurales, etcétera), acordes con las demandas del exterior; la virtualidad como condición para hacer arreglos de cooperación en el espacio cibernético; y la inteligencia, definida como la capacidad para aprender de la propia experiencia que surge en la relación con el otro.

Sobre esta última cuestión, Morgan (1986) plantea que las organizaciones pueden ser asemejadas a sistemas de procesamiento de información, que atrapan y filtran los conocimientos que circulan en el entorno, los procesan en términos de lo que han aprendido, los interpretan, los cambian y actúan sobre ellos.

\section{El tratamiento empírico del fenómeno de las tramas organizacionales}

En cuanto a la metodología utilizada para el estudio de redes institucionales, las investigaciones referidas a esta problemática comienzan por identificar las organizaciones de apoyo a la producción más activas en un territorio concreto, evaluando sus objetivos y alcances. Posteriormente, intentan interpretar los lazos que unen a las distintas organizaciones, diferenciando la mera transmisión de información entre las partes, de aquellos vínculos que suponen un grado de compromiso mayor entre los agentes (Filippi \& Torre, 2003).

En lo que respecta específicamente al análisis de la estructura de la red, los diferentes trabajos incorporan aproximaciones tanto de tipo cuantitativas como cualitativas que ayudan a su mejor caracterización.

Respecto a los enfoques de tipo cuantitativo, la medición de la densidad reticular es el aspecto más estudiado y consiste en identificar la existencia o no de vínculos entre los actores, de tal forma de evaluar el grado de conectividad vigente en el conjunto considerado. La utilización de cualquiera de los índices creados para tal fin resulta útil para conocer el grado de saturación presente en una red, al permitir comparar entramados organizacionales correspondientes a distintos ámbitos territoriales y su evolución, y apreciar su grado de consolidación y madurez a través del tiempo (Caravaca et al, 2005). A este tipo de índices suele agregársele información relativa a la cercanía y centralidad de los agentes, conjuntamente con indicadores 
que consideran la capacidad de mediación en los procesos de comunicación registrados entre los diferentes actores.

En cuanto a la caracterización cualitativa de las redes, los trabajos se focalizan en considerar las propiedades de las relaciones de cooperación entre los agentes, la existencia de una correcta definición de las estructuras de poder y la capacidad de movilización colectiva. En el análisis de las propiedades de la trama, se diferencia entre aquellas de carácter reactivo, que surgen ante la necesidad de responder a problemas ya existentes, y las de carácter proactivo, que buscan descubrir nuevas oportunidades (Méndez, 1998). En este punto, también es importante considerar la coyunturalidad o estabilidad de la cooperación y la existencia o no de una reflexión estratégica que oriente la misma a mediano o largo plazo (Domínguez Ares, 1999; Erbiti, 2004). Por su parte, la caracterización de las estructuras de poder supone analizar el equilibrio o la hegemonía de los agentes y la posible conflictividad o no que pueda originarse entre ellos (Hanneman, 1998).

\section{Pigüé: principales características y entramado institucional}

La localidad de Pigüé se encuentra situada en el sudoeste de la Provincia de Buenos Aires, en la República Argentina (Figura 1). Localizado sobre la pampa húmeda, este núcleo urbano es cabecera del distrito homónimo y cuenta con un total de 14.500 habitantes (Instituto Nacional de Estadística y Censos [INDEC], 2010). Alrededor de la ciudad existe un número significativo de parajes y localidades dormitorio, entre las que se destacan Saavedra (2.200 hab.), Espartillar (1.100 hab.), Arroyo Corto (600 hab.), Goyena (600 hab.) y Dufaur (450 hab.).

\section{FIgURa I | Localización geográfica de Pigüé}

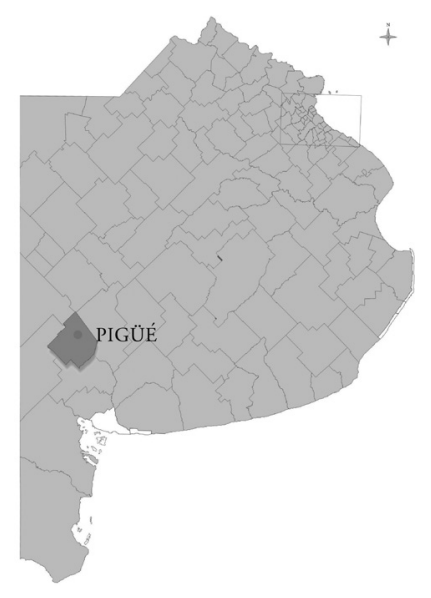

FUENTE ELABORACIÓN PROPIA 
El origen del distrito data de fines del siglo xix, siendo fruto de las corrientes inmigratorias ocurridas en el país durante aquel período, que dieron origen a numerosas colonias agrícolas.

Debido a su excelente suelo y a las importantes precipitaciones que presenta el territorio, el distrito es apto para la producción de trigo, girasol, soja, maíz y sorgo, a lo cual se suma la actividad ganadera de ciclo completo. En total, el partido cuenta con 550 explotaciones agrícolas, que oscilan entre las 200 y 600 hectáreas, existiendo una leve tendencia a la concentración debido a la creciente expansión de la figura del arrendamiento 9 .

En el andamiaje de la economía regional, Pigüé cumple el rol característico de una ciudad pequeña alejada de las grandes urbes: prestación de servicios al campo, suministro de insumos, servicios de asistencia técnica y mano de obra a la producción rural ${ }^{10}$. En forma complementaria a esta actividad principal, emergen en la ciudad numerosos comercios y una creciente actividad industrial ligada al desarrollo de emprendimientos agroalimentarios, metalmecánicos, de textiles y calzado ${ }^{11}$.

En cuanto al entramado institucional del territorio, el mismo ha seguido una trayectoria que resulta paralela al de la economía distrital. En este sentido, en primer término han nacido en el partido las organizaciones ligadas a la actividad agropecuaria, luego las entidades vinculadas al comercio y los servicios, seguidamente de las dedicadas a la educación y a la asistencia técnica (Cuadro 1.)

Pese a la existencia de una importante densidad de organizaciones, no existen en la localidad estudios que se hayan focalizado en conocer su dinámica, comportamiento e incidencia en los procesos de desarrollo económico territorial. No hay evidencia respecto a si las entidades han presentado una importante trayectoria de colaboración a favor del crecimiento económico del partido, por lo que no se contó con antecedentes relevantes que sirvieran de base a la presente investigación. Sin embargo, a partir de las entrevistas realizadas, pudo corroborarse que hoy en día las instituciones no presentan un importante nivel de comunicación, ya que en la práctica se da entre ellas tan solo un $48 \%$ de los vínculos posibles (Figura 2). Así, el análisis de las respuestas de los representantes de las organizaciones entrevistadas respecto de "a quien envían y de quién reciben información"12 arroja la existencia de importantes orificios estructurales en la red de comunicación.

9 De acuerdo con datos de la Secretaría de Estadística de la Provincia de Buenos Aires, la agricultura y la ganadería constituyen el 30\% de la producción bruta distrital.

10 Si se considera la suma de los servicios financieros, inmobiliarios, empresariales y de transporte y almacenamiento, estas actividades conforman el 23,4\% del valor agregado local.

11 La industria representa un 15\% del Producto Geográfico del partido. Por su parte, el comercio alcanza valores cercanos al 9,5\%.

12 Surge de cruzar los datos correspondientes a quién envía y de quién recibe datos cada una de las organizaciones del entramado. La matriz construida para registrar la información es cuadrada, idéntica y normal, ya que permite tanto flujos unidireccionales como bidireccionales. La información registrada en la matriz no contempla la frecuencia de los contactos. 
CUADro I | Organizaciones de apoyo a la producción de Pigüé

\begin{tabular}{|c|c|}
\hline TIPO DE ORGANIZACIÓN & NOMBRE DE LA ENTIDAD \\
\hline \multirow{5}{*}{$\begin{array}{l}\text { Entidades educativas y } \\
\text { científicas }\end{array}$} & Escuela Agropecuaria de Goyena (EAgraria) \\
\hline & Centro de Formación Profesional Nº 401 (CFP N 401) \\
\hline & Escuela de Enseńanza Técnica Nº $1\left(\mathrm{ET} \mathrm{N}^{\circ} 1\right)$ \\
\hline & Asociación Civil de Apoyo a las Actividades Universitarias (ACAU) \\
\hline & Instituto Nacional de Tecnología Agropecuaria (INTA) \\
\hline \multirow[t]{3}{*}{ Banca pública y cooperativa } & Banco de la Nación Argentina (BcoNACION) \\
\hline & Banco de la Provincia de Buenos Aires (BcoPCIA) \\
\hline & Banco CREDICOOP cooperativo limitado (BcoCREDICOOP) \\
\hline \multirow[t]{3}{*}{ Entidades cooperativas } & Cooperativa Apícola Pihué (PIHUÉ) \\
\hline & Cooperativa Agrícola "La Alianza” (ALIANZA) \\
\hline & Cooperativa Eléctrica de Saavedra-Pigüé (CoopElect) \\
\hline \multirow{2}{*}{$\begin{array}{l}\text { Gobierno Local y entidades } \\
\text { gubernamentales }\end{array}$} & Municipalidad de Saavedra-Pigüé (MUNI) \\
\hline & Ministerio de Agricultura, Ganadería, Pesca y Alimentación (MAGPyA) \\
\hline \multirow[t]{2}{*}{ Entidades gremiales } & Cámara de Comercio, Industria, Servicios y Turismo de Pigüé (CCISyT) \\
\hline & Sociedad Rural de Saavedra Pigüé (SRural) \\
\hline Otras organizaciones & Ente Regulador del Sector Industrial (ERSI) \\
\hline
\end{tabular}

FUENTE ELABORACIÓN PROPIA

FIgURA 2 Comunicaciones entre organizaciones en Pigüé

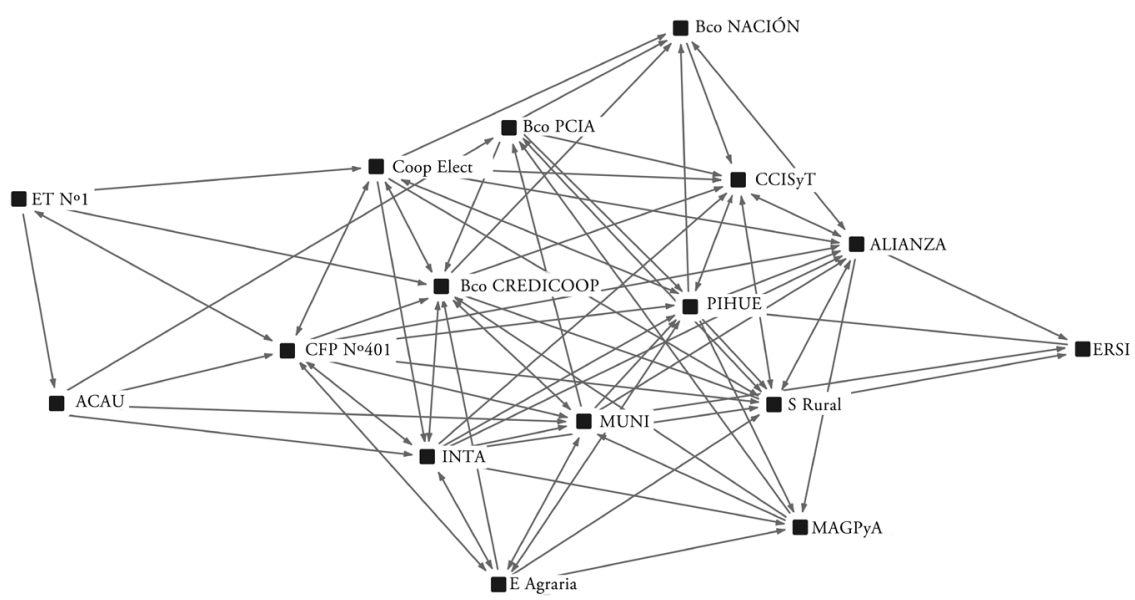

FUENTE ELABORACIÓN PROPIA USANDO UCINET 6.45 Y NETDRAW 2.I 2

A continuación se analiza con más detalle dicha red, a través de diferentes indicadores: grado de centralidad, centralidad de cercanía y centralidad de intermediación. Mediante estas medidas se puede conocer no solamente la posición relativa de cada actor dentro de la trama, sino el funcionamiento y la dinámica global del tejido en su conjunto. 


\section{Las diferentes medidas de análisis de redes sociales}

\section{Grado de centralidad}

En los estudios sobre redes sociales, la medida grado de centralidad muestra el número de actores a los cuales una organización está directamente unida. De acuerdo con este enfoque, las entidades que tienen mayor cantidad de vínculos disponen de una posición ventajosa en la red, ya que pueden acceder a más conocimientos e información, satisfaciendo de esta forma un mayor número de necesidades. El Cuadro 2 muestra la información sobre centralidad correspondiente al grafo de comunicaciones.

CUADRO 2 | Grado de centralidad, red comunicaciones

\begin{tabular}{|l|c|c|c|c|}
\hline ORGANIZACIONES & $\begin{array}{c}\text { LAZOS DE } \\
\text { SALIDA }\end{array}$ & $\begin{array}{c}\text { LAZOS DE } \\
\text { ENTRADA }\end{array}$ & $\begin{array}{c}\text { NORMAL LAZOS } \\
\text { DE SALIDA }\end{array}$ & $\begin{array}{c}\text { NORMAL LAZOS } \\
\text { DE ENTRADA }\end{array}$ \\
\hline MUNI & 12.000 & 11.000 & 80.000 & 73.333 \\
\hline PIHUE & 11.000 & 8.000 & 73.333 & 53.333 \\
\hline INTA & 10.000 & 11.000 & 66.667 & 73.333 \\
\hline ALIANZA & 10.000 & 10.000 & 66.667 & 66.667 \\
\hline CCISyT & 9.000 & 10.000 & 60.000 & 66.667 \\
\hline CoopElect & 9.000 & 8.000 & 60.000 & 53.333 \\
\hline CFP N 401 & 9.000 & 10.000 & 60.000 & 66.667 \\
\hline Bco CREDICOOP & 8.000 & 12.000 & 53.333 & 80.000 \\
\hline BcoPCIA & 7.000 & 2.000 & 46.667 & 13.333 \\
\hline SRural & 7.000 & 10.000 & 46.667 & 66.667 \\
\hline MAGPyA & 6.000 & 4.000 & 40.000 & 26.667 \\
\hline EAgraria & 5.000 & 6.000 & 33.333 & 40.000 \\
\hline BcoNACION & 4.000 & 5.000 & 26.667 & 33.333 \\
\hline ET N 1 & 4.000 & 2.000 & 26.667 & 13.333 \\
\hline ERSI & 3.000 & 2.000 & 20.000 & 13.333 \\
\hline ACAU & 2.000 & 5.000 & 13.333 & 33.333 \\
\hline
\end{tabular}

FUENTE ELABORACIÓN PROPIA USANDO UCINET 6.45

En función de los datos relevados, la organización que más envía información al resto de los actores es la Municipalidad de Pigüé (MUNI), con un total de doce contactos, seguida en orden de importancia por la cooperativa avícola PIHUE con once, el Instituto Nacional de Tecnología Agropecuaria (INTA) y la cooperativa ALIANZA con diez. Este grupo de cuatro actores puede ser considerado como el más influyente en el esquema de relaciones, ya que son los que tienen más capacidad para diseminar en forma autónoma sus ideas a lo largo de la trama considerada.

Siguiendo en orden de importancia, se encuentra un total de tres agentes: la Cámara de Comercio, Industria, Servicios y Turismo de Pigüé (CCIsYT); la Cooperativa Eléctrica del distrito (CoopElect); y el Centro de Formación Profesional (CFP $\mathrm{N} 401$ ), con nueve lazos respectivamente. 
En lo que respecta a la recepción de información (lazos de entrada), la entidad que más se destaca es el Banco Credicoop Cooperativo limitado (CREDicoop) con doce vínculos, seguido en orden de importancia por MUNI e INTA con once. Este último conjunto de instituciones puede considerarse como prestigioso o prominente dentro de la red. El intento por parte del resto de los agentes de compartir conocimientos con ellos puede ser interpretado como un acto de deferencia o reconocimiento de sus posiciones de importancia en el esquema de relaciones.

Con un peso relativo menor, aunque no despreciable, aparecen en segunda instancia cuatro organizaciones: ALIANZA, CCISyT, CFP N 401 y Sociedad Rural (SRural) con diez contactos cada una.

A continuación, se muestran las estadísticas descriptivas de la red (Cuadro 3).

CUADRO 3 | Estadísticas descriptivas, grado de centralidad

\begin{tabular}{|l|r|r|r|r|}
\cline { 2 - 5 } \multicolumn{1}{c|}{} & LAzOS DE SALIDA & $\begin{array}{c}\text { LAZOS DE } \\
\text { ENTRADA }\end{array}$ & $\begin{array}{c}\text { NORMAL LAZOS } \\
\text { DE SALIDA }\end{array}$ & $\begin{array}{c}\text { NORMAL LAZOS } \\
\text { DE ENTRADA }\end{array}$ \\
\hline Promedio & 7.250 & 7.250 & 48.333 & 48.333 \\
\hline Desvío Std & 2.905 & 3.419 & 19.365 & 22.791 \\
\hline Suma & 116.000 & 116.000 & 773.333 & 773.333 \\
\hline Varianza & 8.438 & 11.688 & 375.000 & 519.444 \\
\hline SSQ & 976.000 & 1.028 .000 & 43.377 .777 & 45.688 .887 \\
\hline MCSSQ & 135.000 & 187.000 & 6.000 .000 & 8.311 .111 \\
\hline Euc Norm & 31.241 & 32.062 & 208.273 & 213.750 \\
\hline Mínimo & 2.000 & 2.000 & 13.333 & 13.333 \\
\hline Máximo & 12.000 & 12.000 & 80.000 & 80.000 \\
\hline N of Obs & 16.000 & 16.000 & 16.000 & 16.000 \\
\hline
\end{tabular}

Centralización de la red (lazos de salida) $=36,190 \%$

Centralización de la red (lazos de entrada) $=36,190 \%$

FUENTE ELABORACIÓN PROPIA USANDO UCINET 6.45

De acuerdo con la información del Cuadro 3, puede observarse que, en promedio, los actores tienen un total de siete lazos de entrada y salida respectivamente. Si bien este valor puede considerarse elevado, el desvío estándar (tanto de salida como de entrada) también es alto, lo que indica la existencia de posiciones heterogéneas en la red. Esta situación puede corroborarse a partir de la información sobre lazos mínimos y máximos de entrada y salida, que muestra una fluctuación importante.

Por último, las medidas de centralización de grafo de Freeman muestran valores que no son del todo significativos (36\% de entrada y salida, respectivamente), lo que evidencia la ausencia de una concentración importante de vínculos en un número muy reducido de actores.

\section{Centralidad de cercanía}

Como se sostuvo en el apartado anterior, la medida grado de centralidad muestra solo los vínculos inmediatos o lazos directos que tiene cada actor y no considera los contactos que una organización puede establecer en forma indirecta, es decir, aquellos 
que se producen utilizando otro agente como puente. Esta última tipología de contacto resulta de importancia en la medida en que los agentes no solo hacen circular por el ámbito de la red información propia, sino también conocimientos de terceros.

El enfoque de centralidad de cercanía ${ }^{13}$, a diferencia de la medida grado de centralidad, no enfatiza la naturaleza del vínculo que une a los actores, sino que hace hincapié en la distancia de un actor a otro, concentrándose en lo que se conoce como la distancia geodésica, es decir, la ruta más corta que un agente debe seguir para llegar a otro nodo. Los resultados de la centralidad de cercanía para la red comunicaciones se presentan a continuación (Cuadro 4).

CUADRO 4 Centralidad de cercanía, red comunicaciones

\begin{tabular}{|l|c|c|}
\hline \multicolumn{1}{|c|}{ ORGANIZACIONES } & CERCANÍA DE ENTRADA & CERCANÍA DE SALIDA \\
\hline Bco CREDICOOP & 83.333 & 68.182 \\
\hline INTA & 78.947 & 75.000 \\
\hline MUNI & 78.947 & 83.333 \\
\hline CCISyT & 75.000 & 71.429 \\
\hline CFP N 401 & 75.000 & 71.429 \\
\hline SRural & 75.000 & 65.217 \\
\hline ALIANZA & 75.000 & 75.000 \\
\hline CoopElect & 68.182 & 71.429 \\
\hline PIHUE & 68.182 & 78.947 \\
\hline EAgraria & 60.000 & 60.000 \\
\hline ACAU & 57.692 & 48.387 \\
\hline BcoNACION & 57.692 & 51.724 \\
\hline MAGPyA & 55.556 & 62.500 \\
\hline ET N 1 & 51.724 & 51.724 \\
\hline ERSI & 50.000 & 53.571 \\
\hline BcoPCIA & 48.387 & 65.217 \\
\hline
\end{tabular}

FUENTE ELABORACIÓN PROPIA USANDO UCINET 6.45

El análisis de los datos muestra que los actores más cercanos al resto por grado de salida son MUNI y PIHUE, con 83 y 78 caminos geodésicos, respectivamente. En orden de importancia aparecen luego el INTA y la cooperativa la ALIANZA, que se encuentran en 75 caminos geodésicos.

En lo que respecta a los grados de entrada, destaca en primer término el caso de BCo CREDICOOP, que se encuentra en 83 caminos geodésicos, seguido de MUNI e INTA. Posteriormente, aparecen como actores relevantes CCISyT, CFP $\mathrm{N}^{\circ} 41$, SRural y ALIANZA.

13 El enfoque de centralidad de cercanía se utiliza habitualmente en matrices simétricas, pero UCINET permite calcular la medida para matrices normales, diferenciando entre cercanía por lazos de entrada y cercanía por lazos de salida. 
CUADRO 5 | Estadísticas descriptivas, centralidad de cercanía

\begin{tabular}{|l|c|c|}
\cline { 2 - 3 } \multicolumn{1}{c|}{} & CERCANÍA DE ENTRADA & CERCANÍA DE SALIDA \\
\hline Promedio & 66.165 & 65.818 \\
\hline Desvío Std & 11.241 & 10.138 \\
\hline Suma & 1.058 .643 & 1.053 .090 \\
\hline Varianza & 126.371 & 102.780 \\
\hline SSQ & 72.067 .258 & 70.956 .859 \\
\hline MCSSQ & 2.021 .934 & 1.644 .477 \\
\hline Euc Norm & 268.453 & 266.377 \\
\hline Mínimo & 48.387 & 48.387 \\
\hline Máximo & 83.333 & 83.333 \\
\hline N of Obs & 16.000 & 16.000 \\
\hline
\end{tabular}

Centralización de la red entrada $=37,93 \%$.

Centralización de la red salida $=38,70 \%$

FUENTE ELABORACIÓN PROPIA USANDO UCINET 6.45

Por su parte, la información relativa a las estadísticas descriptivas (Cuadro 5) arroja que existe un promedio por actor de 65 caminos geodésicos por grado de salida y de 66 por grado de entrada, siendo el desvío estándar bastante alto, entre 10 y 11 respectivamente. A su vez, se observa nuevamente una importante distancia entre la cantidad de caminos geodésicos máximos y mínimos, lo cual da cuenta de heterogeneidad de ubicaciones en la trama.

Finalmente, los índices de centralidad corroboran la información registrada en el indicador anterior, ya que marcan la ausencia de una condensación excesiva de relaciones en un núcleo muy pequeño de actores.

\section{Grado de intermediación}

Además de la importancia que un actor puede tener debido a su centralidad en el esquema de relaciones, su relevancia dentro de una red también puede estar marcada por su capacidad para controlar la comunicación entre las diversas organizaciones. La medida de grado de intermediación intenta captar este fenómeno, considerando todos los caminos geodésicos posibles entre los pares de nodos existentes en la red. A través de esta medida, se intenta captar la capacidad que tiene una organización para difundir ideas e información en la trama (ya sea propia o de terceros) o también de censurarla, a través de la mediación que puede ejercer con agentes alejados del núcleo de relaciones.

El Cuadro 6 muestra la información correspondiente a la habilidad de intermediación de los distintos agentes.

Según los datos relevados, la mayor capacidad de intermediación se encuentra en el actor MUNI, seguido en orden de importancia por el CFP $\mathrm{N}^{\circ} 401$, el Bco CREDICOOP y el InTA. Por su parte, si se analiza este indicador en términos porcentuales, se observa una elevada habilidad de mediación por parte de MUNI, superior al 14\%. También resulta muy significativa la capacidad de arbitraje de los actores CFP N 401 $(8,75 \%)$, Bco CREDICOOP $(8,71 \%)$ e INTA $(7,64 \%)$ respectivamente. 
CUADRO 6 | Grado de intermediación, red comunicaciones

\begin{tabular}{|l|c|c|}
\hline \multicolumn{1}{|c|}{ ORGANIZACIONES } & INTERMEDIACIÓN & NORMAL DE INTERMEDIACIÓN \\
\hline MUNI & 29.995 & 14.283 \\
\hline CFP N 401 & 18.391 & 8.758 \\
\hline Bco CREDICOOP & 18.291 & 8.710 \\
\hline INTA & 16.045 & 7.641 \\
\hline CCISyT & 10.814 & 5.150 \\
\hline PIHUE & 10.803 & 5.144 \\
\hline ALIANZA & 10.250 & 4.881 \\
\hline CoopElect & 8.198 & 3.904 \\
\hline SRural & 4.816 & 2.293 \\
\hline MAGPyA & 2.253 & 1.073 \\
\hline BcoPCIA & 2.017 & 0.960 \\
\hline ACAU & 0.700 & 0.333 \\
\hline ET N 1 & 0.685 & 0.326 \\
\hline EAgraria & 0.575 & 0.274 \\
\hline BcoNACION & 0.167 & 0.079 \\
\hline ERSI & 0.000 & 0.000 \\
\hline
\end{tabular}

FUENTE ELABORACIÓN PROPIA USANDO UCINET 6.45

Finalmente, en lo que se refiere a las estadísticas descriptivas del indicador (Cuadro 7), se muestra que la capacidad de intermediación promedio es de 8 caminos geodésicos, siendo el desvío estándar de igual magnitud. El valor mínimo de intermediación alcanza un nivel de 0 y el máximo de 29 para el total de las 16 observaciones.

CUADRO 7 | Estadísticas descriptivas, grado de intermediación

\begin{tabular}{|l|c|c|}
\cline { 2 - 3 } \multicolumn{1}{c|}{} & INTERMEDIACIÓN & NORMAL DE INTERMEDIACIÓN \\
\hline Promedio & 8.375 & 3.988 \\
\hline Desvío Std & 8.468 & 4.032 \\
\hline Suma & 134.000 & 63.810 \\
\hline Varianza & 71.706 & 16.260 \\
\hline SSQ & 2.269 .542 & 514.635 \\
\hline MCSSQ & 1.147 .291 & 260.157 \\
\hline Euc Norm & 47.640 & 22.686 \\
\hline Mínimo & 0.000 & 0.000 \\
\hline Máximo & 29.995 & 14.283 \\
\hline N of Obs & 16.000 & 16.000 \\
\hline
\end{tabular}

Centralización de la red por intermediación $=10,98 \%$

FUENTE ELABORACIÓN PROPIA USANDO UCINET 6.45 
De acuerdo con la información suministrada por el programa, la centralidad de la red en su conjunto alcanza un valor del $10,98 \%$, lo cual muestra que la capacidad del sistema en su conjunto para mediar es relativamente baja.

\section{Proyectos conjuntos}

Una alternativa para evaluar las relaciones existentes entre diversas organizaciones es considerar la cantidad de proyectos económicos conjuntos que las unen o las vinculan entre sí.

Según Flores (1989), el diseño de un proyecto conjunto entre dos o más entidades implica un estadio superior de comunicación, donde se afianzan conversaciones y compromisos y se establece un nivel de coordinación que obliga a la producción sistemática de información consensuada entre las partes. Los lazos que surgen entre las entidades a partir de estas actividades constituyen, en términos de Wasserman y Faust, lazos fuertes que actúan como una suerte de capital sinergético (Boisier, 1993), en el sentido de que el vínculo no suele agotarse con la finalización del proyecto, sino que puede potenciarse, dando origen a nuevas iniciativas a través del tiempo.

De acuerdo con el Instituto Latinoamericano de Planificación Económica y Social (ILPES, 1966), se entiende por proyecto económico a una unidad de actividades de cualquier naturaleza, que requiere para su realización del uso o consumo de recursos escasos sacrificando beneficios actuales y asegurados, con la esperanza de obtener, en un período de tiempo mayor, beneficios superiores a los que se obtienen con la asignación actual de dichos recursos. La Figura 3 refleja los lazos establecidos por las entidades pigüenses a partir de diversos proyectos económicos.

\section{FIgURA 3 | Proyectos conjuntos entre organizaciones en Pigüé}

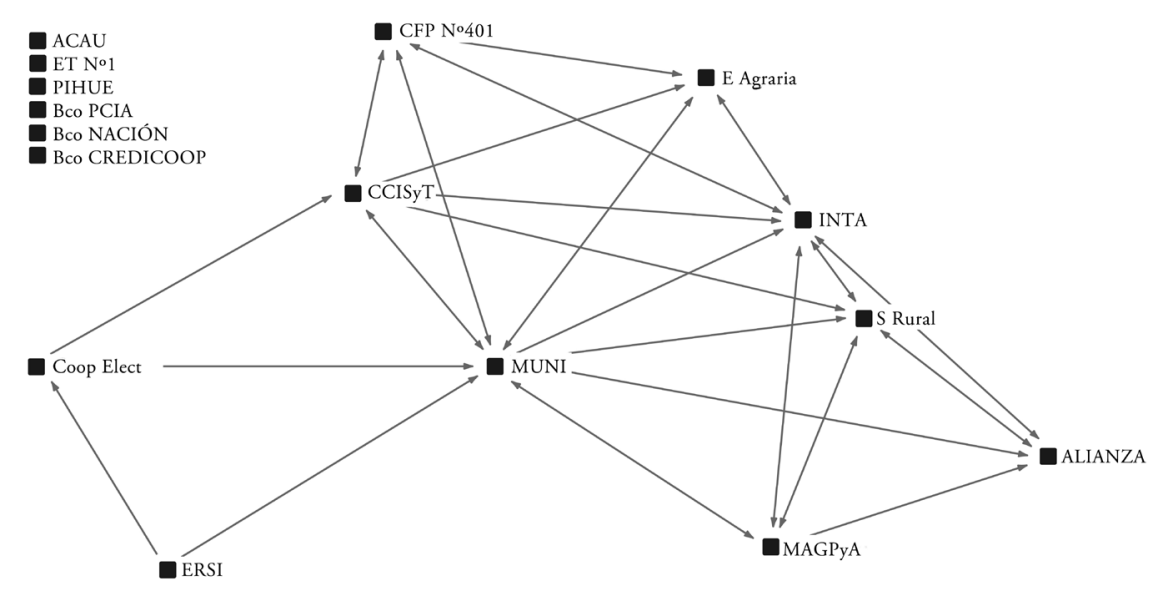

FUENTE ELABORACIÓN PROPIA USANDO UCINET 6.45 Y NETDRAW 2.I 2 
Este tipo concreto de redes se conoce como redes de afiliación o redes de implicancia mutua (Wasserman \& Faust, 1994), ya que el vínculo entre dos actores se forma cuando ambas organizaciones declaran estar realizando un proyecto en forma conjunta.

En función de la información suministrada por las organizaciones al momento de las entrevistas, se reconoció un total de 19 proyectos de colaboración en ejecución, que involucran a dos o más instituciones. Este número puede ser considerado bajo si se lo compara con trabajos realizados para otras localidades de Argentina ${ }^{14}$. En lo que respecta a su temática, cuatro se refieren a comercialización de diversos productos locales $(21 \%)$, cuatro a la generación de infraestructura física para el distrito $(21 \%)$, tres corresponden a la implementación y puesta a punto de infraestructura tecnológica (16\%), tres a capacitación (16\%), dos constituyen proyectos de administración y coordinación de recursos (10\%), dos apuntan a la implementación de nuevos negocios (10\%) y uno tiene como objetivo el diseńo de actividades de investigación y desarrollo (5\%).

\section{CUADRo 8 | Proyectos conjuntos}

\begin{tabular}{|c|c|c|c|}
\hline $\mathbf{N}^{0}$ & NOMBRE DEL PROYECTO & TIPO DE PROYECTO & $\begin{array}{l}\text { ORGANIZACIONES } \\
\text { INTERVINIENTES }\end{array}$ \\
\hline 1 & Curso de maquinista profesional & Capacitación & CFT No 401 e INTA \\
\hline 2 & Mesa de cogestión & $\begin{array}{l}\text { Administración y coordinación } \\
\text { de recursos }\end{array}$ & $\begin{array}{l}\text { CFT No 401, INTA, EA- } \\
\text { graria CCISyT, MUNI }\end{array}$ \\
\hline 3 & Feria permanente de artesanos & Comercialización de productos & INTA MUNI \\
\hline 4 & Curso de remallado & Capacitación & CFT N $^{\circ} 401$ e MUNI \\
\hline 5 & Emergencia agropecuaria & $\begin{array}{l}\text { Administración y coordinación } \\
\text { de recursos }\end{array}$ & $\begin{array}{l}\text { MUNI, S Rural, MAGPyA, } \\
\text { INTA, ALIANZA }\end{array}$ \\
\hline 6 & $\begin{array}{l}\text { Plan de mejora tecnológica de } \\
\text { comercios }\end{array}$ & Infraestructura tecnológica & MUNI y CCISyT \\
\hline 7 & Reacondicionamiento de silos & Infraestructura física & MUNI ALIANZA \\
\hline 8 & Electrificación del parque industrial & Infraestructura física & MUNI CoopElect \\
\hline 9 & Fábrica de chacinados & Desarrollo de nuevos negocios & MUNI EAgraria S Rural \\
\hline 10 & $\begin{array}{l}\text { Implantación de nuevas razas } \\
\text { vacunas }\end{array}$ & Desarrollo de nuevos negocios & MUNI EAgraria \\
\hline 11 & Exposición anual de productos & Comercialización de productos & CCISyT, S Rural, MUNI \\
\hline 12 & Red de servicio de celulares & Infraestructura tecnológica & CoopElect CCISyT \\
\hline 13 & Plan Megatel & Comercialización de productos & CoopElect CCISyT \\
\hline 14 & Provisión de gas natural & Infraestructura física & $\begin{array}{l}\text { CoopElect CCISyT y } \\
\text { MUNI }\end{array}$ \\
\hline 15 & Nuestro & Comercialización de productos & CoopElect CCISyT \\
\hline 16 & Red de fibra óptica & Infraestructura tecnológica & CoopElect MUNI \\
\hline 17 & Ensayos de nutrición animal & Actividades de I + D & INTA EAgraria \\
\hline 18 & Terneros & Infraestructura física & S Rural EAgraria \\
\hline 19 & Identidad productiva & Capacitación & EAgraria INTA \\
\hline
\end{tabular}

FUENTE ELABORACIÓN PROPIA

14 A modo de ejemplo, Ferraro y Costamagna (2002), en su trabajo sobre la ciudad de Mar del Plata, identificaron un total de 142 proyectos conjuntos entre 27 organizaciones estudiadas. 
La entidad que más proyectos declaró tener fue la Municipalidad de Pigüé (MUNI), con un total de doce $(63,16 \%$ del total), seguido en orden de importancia por la Cámara de Comercio, Industria, Servicios y Turismo (CCISyT) con siete (37\%) y el INTA, CoopElect y EAgraria con participación en seis (31\%) respectivamente. A la vez, se observa que un total de seis organizaciones (ACAU, ET $\mathrm{N}^{\circ} 1$, PIHUE, BcoPCIA, BcoNACION, BcoCREDICOOP) no dispone de iniciativas conjuntas con otros agentes (Figura 3). Por su parte, del total de proyectos relevados, solo siete $(36,84 \%$ del total) están conformados por más de dos entidades del entramado, lo cual puede significar cierto condicionamiento o limitación por parte de las entidades para compartir recursos con un número importante de actores.

\section{Liderazgos}

Entre los principales referentes de la economía regional, Rubén Utria (1981) plantea como elemento fundamental de las posibilidades de desarrollo territorial, el grado de organización existente en una comunidad. Según el autor, una sociedad dinámica que experimenta un cambio activo a favor del desarrollo contiene en su seno una dosis de conflicto y de puja de intereses, pero en la búsqueda del progreso social y económico, la población debe estar integrada para asegurar un grado razonable de acuerdo y de unidad de acción. Desde esta visión, resulta de suma importancia el papel que desempeńan las organizaciones territoriales y sus líderes como catalizadores y guías de la ciudadanía, capaces de impulsar una estrategia que contenga y sintetice diferentes aspiraciones. Esta perspectiva supone que cuanto más eficiente es la organización del territorio y genuino el liderazgo institucional, más está la comunidad local en condiciones de cumplir una función activa y eficiente en las tareas del desarrollo. En este ámbito, se entiende por liderazgo institucional a la habilidad de una organización para, sobre la base de cualidades propias, obtener la subordinación voluntaria de otras entidades en una gama amplia de asuntos.

Para intentar evaluar la presencia o ausencia de liderazgos de esta naturaleza, D’Annunzio (2000), Costamagna (2000) y Ferraro y Costamagna (2002) desarrollaron una metodología que permite el estudio de cuatro puntos clave para el desarrollo económico territorial. Ella consiste en instar a los referentes locales a nombrar de manera objetiva a tres agentes que consideran líderes en cuatro temas, existiendo la posibilidad de autoevaluación. Los temas por considerar son los siguientes:

- Generación de iniciativas y propuestas.

- Capacidad para articular y generar consenso entre las distintas entidades.

- Capacidad de negociación con actores externos al ámbito local.

- Visión estratégica de futuro respecto a temas vinculados al desarrollo económico del territorio en cuestión.

A partir de estos criterios, los resultados destacan el papel de un actor (MUNI) como principal líder del andamiaje institucional, ya que el mismo obtiene valores superiores al $50 \%$ en todos los indicadores, con excepción del correspondiente a Visión Estratégica de Futuro. 


\section{GRÁFICO I Indicador, iniciativas y propuestas}

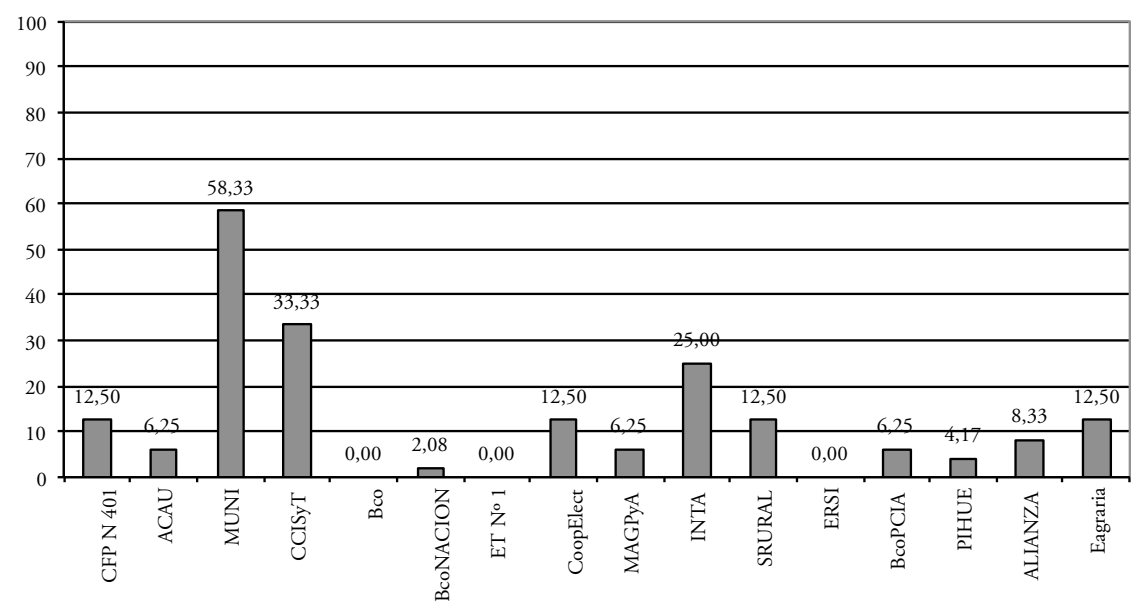

FUENTE ELABORACIÓN PROPIA CON BASE EN ENTREVISTAS REALIZADAS

En el primer indicador, Iniciativas y Propuestas, MUNI obtiene un 58,3\%, seguido en orden de importancia por CCISyT, con 33,3\%, e INTA con 25\%, mientras que el resto de los actores obtiene valores que no pueden considerarse significativos (Gráfico 1).

\section{GRÁFICO 2| Indicador Articulación y Generación de Consenso}

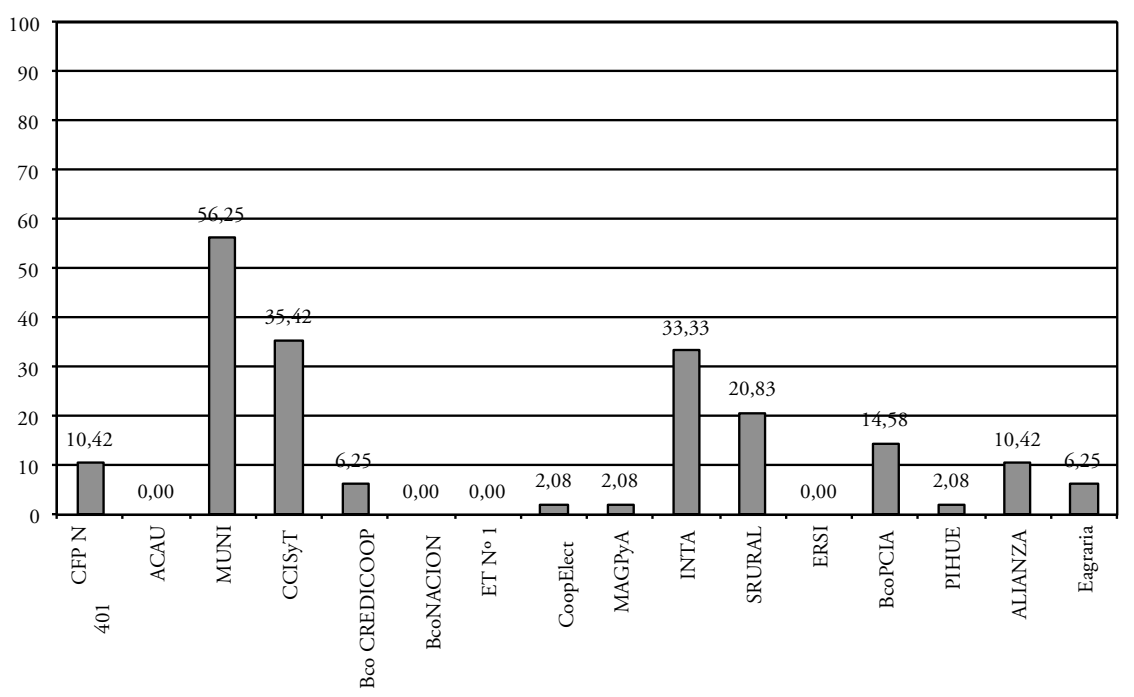

FUENTE ELABORACIÓN PROPIA CON BASE EN ENTREVISTAS REALIZADAS 
En lo que respecta a la Capacidad para articular y generar consenso (Gráfico 2), los actores resaltan en primer lugar el caso de MUNI, con un 56\% del valor del índice, apareciendo nuevamente en segundo lugar CCISyT, con 35\%, e INTA con 33\%, respectivamente.

\section{GRÁfICO 3 | Indicador Capacidad de Negociación}

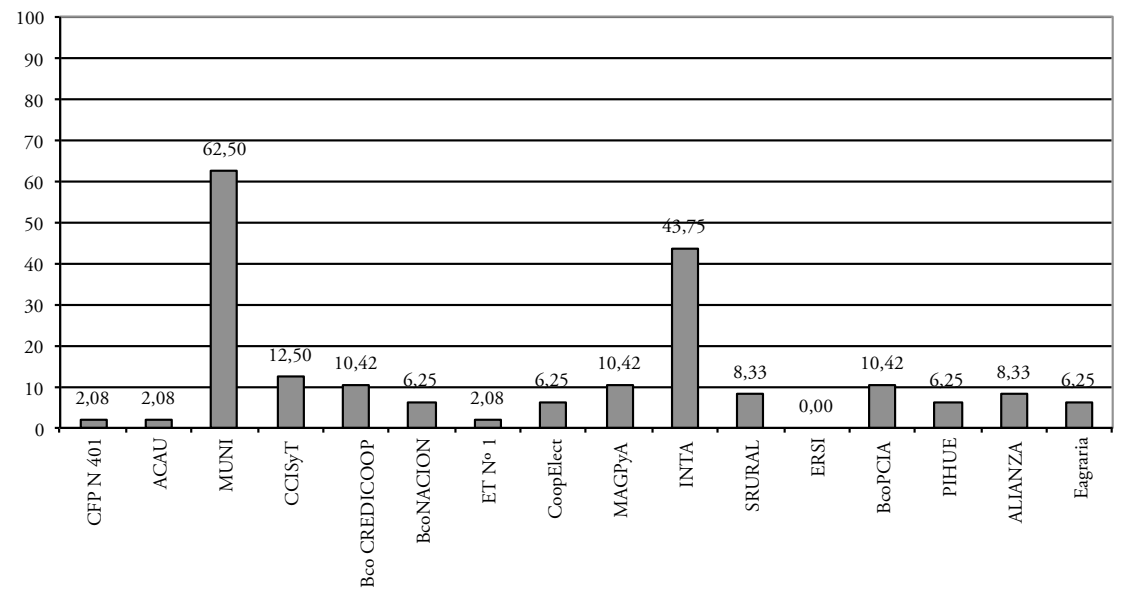

FUENTE ELABORACIÓN PROPIA CON BASE EN ENTREVISTAS REALIZADAS

En tercer término, el índice Capacidad de Negociación (Gráfico 3) nuevamente vuelve a marcar a los mismos tres actores como los más relevantes, aunque destacando la figura de MUNI (62\%) e INTA (43\%) por sobre CCISyT, que en este caso obtiene un valor casi despreciable (12\%).

\section{GRÁFICO $4 \mid$ Indicador Visión Estratégica}

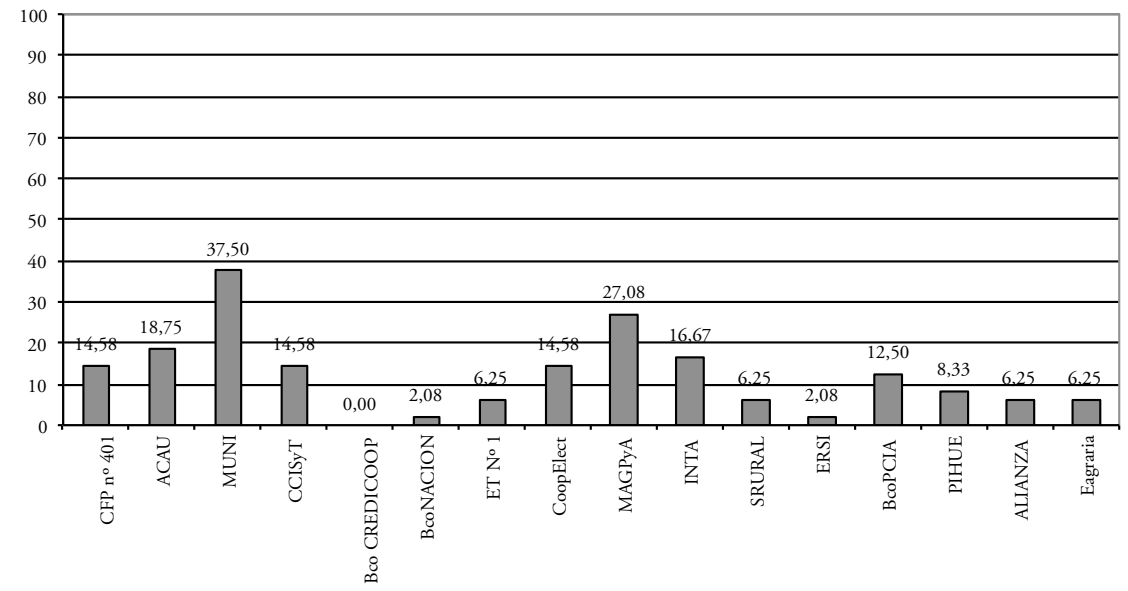

FUENTE ELABORACIÓN PROPIA CON BASE EN ENTREVISTAS REALIZADAS 
Finalmente, en lo que respecta a la Visión Estratégica de Futuro (Gráfico 4), aparece nuevamente MUNI liderando el indicador, pero con valores muy inferiores a los obtenidos anteriormente (37,5\%). En segundo y tercer lugar, destacan en este caso la oficina local del Ministerio de Agricultura, Ganadería, Pesca y Alimentación (MAGPyA, 27\%) y la Asociación Civil de Actividades Universitarias (ACAU, 18\%) ${ }^{15}$. Como hecho relevante, resulta importante resaltar que un número significativo de organizaciones consideró que no existían entidades con Visión Estratégica en el partido, mientras que otras tuvieron dificultades para identificar tres actores que cumplieran con esta característica.

\section{Conclusiones}

En el ámbito de la geografía y de la economía urbana y regional, existe un creciente interés en el papel que pueden desempeñar las ciudades pequeñas como instrumentos capaces de favorecer el desarrollo de sistemas urbanos más equilibrados.

Entre los elementos clave que permiten el crecimiento y consolidación de estos núcleos poblacionales, se encuentran las redes institucionales. Estas redes son un insumo básico para la promoción de la competitividad urbana, ya que incentivan la transformación económica y social de los territorios.

Como bien sostienen Michellini y Davies (2009), los actores institucionales públicos y privados- tienen un rol significativo en el desarrollo de una localidad. Las características y la capacidad de coordinación del contexto institucional (Amin \& Thrift, 1995), en función de proyectos concretos y de una visión de futuro del territorio, constituyen frecuentemente un rasgo distintivo de sus potencialidades. A su vez, en el contexto actual de la economía mundial, la capacidad de dichas entidades para aprender de los cambios en el entorno y generar y difundir conocimiento en el ámbito local -social o empresarial- es un elemento destacado en la literatura como incentivador del crecimiento y la acumulación de capital.

En el caso particular de la localidad de Pigüé, puede observarse que las organizaciones presentan dificultades para comunicarse adecuadamente. De acuerdo con la información suministrada por los entrevistados, solo está presente un $48 \%$ de los intercambios posibles (densidad de comunicaciones media-baja), lo cual muestra la presencia de importantes orificios estructurales en la red. Esta limitación en los procesos de intercambio de conocimientos e información se traduce en una pobre cantidad de proyectos conjuntos, de los cuales existen únicamente diecinueve. Al mismo tiempo, existe un número significativo de entidades (seis) que manifestaron no desarrollar ninguna iniciativa de colaboración con otras organizaciones del medio.

En función de estos resultados, puede asegurarse que el entramado institucional de apoyo a la producción tiene escasa incidencia sobre las posibilidades de desarrollo del territorio en cuestión. Sin embargo, un análisis más pormenorizado del papel de cada uno de los actores entrevistados permite identificar aquellos agentes con mayor y menor capacidad para alterar la dinámica institucional observada. $\mathrm{Al}$ respecto, el estudio del proceso de comunicaciones registrado en Pigüé destaca el

En este caso, INTA y CCISyT aparecen en $4^{\circ}$ y $5^{\circ}$ lugar, respectivamente. 
papel de la Municipalidad (MUNI) por sobre el resto de los agentes entrevistados. Esta organización demostró tener una importante incidencia en el envío y recepción de información (doce lazos de salida y once de entrada), situación que le otorga también un peso significativo en los indicadores de centralidad de cercanía y centralidad de intermediación.

El importante predicamento de esta institución queda también evidenciado en la cantidad de proyectos que desarrolla con otras entidades del entramado (doce), siendo la organización líder en este rubro. Su peso se demuestra, además, en su relevancia en los indicadores Iniciativas y Propuestas, Articulación y Generación de Consenso, Capacidad de Negociación y Visión Estratégica de Futuro, ya que obtiene los valores más altos en cada uno de estos puntos.

En orden de importancia, pueden destacarse luego los casos del INTA y la CCISyT. Estos dos actores también han logrado capitalizar su peso en la red de comunicaciones a través de proyectos, condición que les ha permitido posicionarse positivamente en los índices de liderazgo.

Como contracara, pueden citarse los casos del Banco Credicoop (CREDicoop) y la Cooperativa Pihué (PIHUE). Estos agentes no han logrado traducir en verdaderas actividades de colaboración, que mejoren la dinámica económica distrital, su injerencia en los procesos de comunicación. A raíz de ello, el peso específico que presentan en los indicadores anteriormente mencionados resulta prácticamente despreciable.

Finalmente, a modo de reflexión, puede decirse que los tres actores principales (MUNI, INTA y CCISyT) deben trabajar en pos de alcanzar redes de comunicación más densas y complejas, que mejoren la incidencia de la trama institucional sobre las posibilidades de crecimiento y acumulación de capital de la localidad. Estos agentes constituyen "organizadores naturales" de los procesos de interacción y pueden actuar como "facilitadores", acercando posiciones entre diversas organizaciones. En este sentido, también pueden desempeñar un papel de importancia al actuar también como "traductores" entre entidades que presentan códigos, lenguajes y formas de trabajo diferentes. A través de estas acciones lograrán seguramente conformar espacios de colaboración más amplios, que exploten más adecuadamente todas las sinergias posibles, haciendo posible alcanzar mayores niveles de innovación, transferencia de conocimientos e inversión, que repercutan en una mejora en el empleo, la calidad de vida y el bienestar de la población de Pigüé.

\section{Referencias bibliográfícas}

Amin, A. \& Thrift, N. (1995). Institutional issues for the European regions: from markets and plans to socioeconomics and power of association. Economy and Society, 24(1), 41-66. doi: 10.1080/03085149500000002

Bennett, R. \& Krebs, G. (1994). Local economic development partnerships: an analysis of policy networks in ECLEDA local employment development strategies. Journal of Regional Studies, 28(2), 119-140. 
Best, M. (1990). The new competition. Institutions of industrial restructuring, Cambridge: Polity Press.

Bianchi, P. \& Miller, L. (2000). Innovación, acción colectiva y crecimiento endógeno: un ensayo sobre las instituciones y el cambio estructural. En F. Boscherini \& L. Poma, L. (Comps.), Territorio, conocimiento y competitividad de las empresas. El rol de las instituciones en el espacio global (pp. 77-99). Buenos Aires: Miño y Dávila Editores.

Boisier, S. (1997). El vuelo de una cometa. Una metáfora para una teoría del desarrollo territorial. Serie Ensayos ILPES no 37. Santiago de Chile: Instituto Latinoamericano de Planificación Económica y Social (ILPES).

Borgatti, S. P., Everett, M. G. \& Freeman, L. C. (2002). Ucinet for Windows: Software for Social Network Analysis. Harvard, MA: Analytic Technologies.

Boudeville, J. (1965). Los espacios económicos. Buenos Aires: Eudeba.

Camagni, R. (1991). Innovation Networks: spatial perspectives. Nueva York: Belhaven Press.

Capel, H. (2009). Las pequeñas ciudades en la urbanización generalizada y ante la crisis global. Investigaciones Geográficas, 70, 7-32. doi: http://dx.doi.org/10.14350/rig.18075

Caravaca, I., González, G. \& Silva, R. (2005). Innovación, redes, recursos patrimoniales y desarrollo territorial. EURE, 31(94), 5-24. En http://www.eure.cl/index.php/eure/ article/view/1332

Córo, G. (2000). Contingencia, aprendizaje y evolución en los sistemas productivos locales. En F. Boscherini \& L. Poma, L. (Comps.), Territorio, conocimiento y competitividad de las empresas. El rol de las instituciones en el espacio global (pp. 295-339). Buenos Aires: Miño y Dávila Editores.

Costamagna, P. (2000). La articulación y la interacción entre instituciones: la iniciativa de desarrollo económico local de Rafaela, Argentina. Santiago de Chile: Naciones Unidas.

D’Annuzio, C. (2000). Iniciativa de desarrollo económico local. La articulación y las interacciones entre instituciones: el caso Tandil, Argentina. Santiago de Chile: Naciones Unidas.

Diez, J. (2010). Desarrollo endógeno en Bahía Blanca: empresas, organizaciones y políticas públicas. Bahía Blanca: Ediuns (Editorial de la Universidad Nacional del Sur).

Domínguez Ares, E. (1999). Las organizaciones como instrumento de desarrollo local. Trabajo Profesional Fin de Carrera (inédito), Escuela Técnica Superior de Ingenieros Agrónomos y de Montes Universidad de Córdoba, Espańa.

Erbiti, C. (2004). Los condicionantes del desarrollo endógeno en las ciudades de la macrorregión pampeana: el caso Tandil, Argentina. Tesis Doctoral (inédito). Facultad de Filosofía y Letras, Universidad Autónoma de Madrid, España.

Faludi, A. (2005). La política de cohesión territorial de la Unión Europea. Boletín de la Asociación de Geógrafos Españoles, 39, 11-30. En http://dialnet.unirioja.es/servlet/ articulo? codigo $=1161228$

Ferraro, C. \& Costamagna, P. (2002). Competitividad territorial e instituciones de apoyo a la producción en Mar del Plata. Santiago de Chile: Naciones Unidas.

Filippi, M. \& Torre, A. (2003). L'organisation en réseau: de l'instauration de règles locales aux actions collectives. En A. Dupuy \& A. Burmeister (Eds.), Enterprises et territories. Les nouveaux enjeux de la proximité. París: La Documentation Française.

Hanneman, R. (1998). Introducción a los métodos de análisis de redes sociales. Riverside, CA: University of California, Riverside. En http://revista-redes.rediris.es/webredes/text. htm 
Harrigan, K. (1992). Joint Venture. Buenos Aires: Tesis-Norma.

Instituto Latinoamericano de Planificación Económica y Social (ILPEs). (1966). Discusiones sobre planificación. Santiago de Chile: Editorial Siglo XxI.

Instituto Nacional de Estadística y Censos (INDEC), República Argentina. (2010). Censo Nacional de Población, Hogares y Vivienda 2010. En http://www.censo2010.indec. gov.ar/

MacLeod, G. \& Goodwin, M. (1999). Space, scale and state strategy: Rethinking urban and regional governance. Progress in Human Geography, 23(4), 503-527. doi: 10.1191/030913299669861026

Meadows, D. H., Meadows, D. L., Randers, J. \& Beherens III, W. W. (1972). The limits to growth. A report for The Club of Rome's Project on the Predicament of Mankind. Nueva York, Universe Books/Signet Books. En http://bit.ly/1wzIwvn. [Versión en español: Los limites del crecimiento: Informe al Club de Roma sobre el predicamento de la humanidad. México: Fondo de Cultura Económica, 1972].

Méndez, R. (1997). Geografía económica. La lógica espacial del capitalismo global. Barcelona: Ariel.

Méndez, R. (1998). Innovación tecnológica y reorganización del espacio industrial: una propuesta metodológica. EURE, 24(73), 31-54. http://dx.doi.org/10.4067/S025071611998007300002

Michellini, J. \& Davies, C. (2009). Ciudades intermedias y desarrollo territorial: un análisis exploratorio del caso argentino. Documento de Trabajo no 5 . Grupo de Estudios sobre Desarrollo Urbano (GEDEUR). Madrid: GEDEUR.

Morgan, G. (1986). Imágenes de las organizaciones. México D.F.: Alfaomega.

Paelinck, J. (1963). La teoría del desarrollo regional polarizado. Revista de Economía Latinoamericana, 3(9), 22-47.

Perroux, F. (1955). Note sur la Notion de Pôle de Croissance. Économie Appliquée, 8(17), 15-29.

Sassone, M. S. (1992). Subsistemas urbanos policéntricos en los sistemas nacionales de ciudades. Un caso en la Argentina. Revista Geográfica, 116, 85-111.

Sassone, M. S. (2000). Reestructuración territorial y ciudades intermedias en Argentina. Ciudad y Territorio. Estudios Territoriales, 32(123), 57-92. En http://p3.usal.edu.ar/ index.php/signos/article/view/2314

Utria, R. (1981). Algunos aspectos sociales del desarrollo regional en América Latina. En A. Kuklinski (Comp.), Aspectos sociales de la politica y de la planeación regional. México, D.F.: Fondo de Cultura Económica.

Vapñarsky, C. (1995). Primacía y macrocefalia en Argentina: la transformación del sistema de asentamiento humano desde 1950. Desarrollo Económico, 35(138), 227-254.

Vapñarsky, C. (2004). Cuando el caos caracteriza la división oficial del territorio del Estado. A propósito de los municipios argentinos. Scripta Nova, 8(162). En http://www.ub.edu/ geocrit/sn/sn-162.htm

Vázquez Barquero, A. (1993). Politica económica local: La respuesta de las ciudades a los desafíos del ajuste productivo. Madrid: Ediciones Pirámide.

Vieytes, R. (2004). Metodología de la investigación en organizaciones, mercado y sociedad. Epistemología y técnicas. Buenos Aires: Editorial de las Ciencias.

Wasserman, S. \& Faust, K. (1994). Social Network Analysis. Methods and Applications. Cambridge: Cambridge University Press. En http://train.ed.psu.edu/WFED-543/ SocNet_TheoryApp.pdf 
